\title{
Postacute-Stroke Management Problems in Home Care Service: A Qualitative Single- Centered Study in Yogyakarta, Indonesia
}

\author{
Paryono $^{1}$ Mawaddah Ar Rochmah ${ }^{1}$ Ismail Setyopranoto ${ }^{1}$ Laksono Trisnantoro ${ }^{2}$ \\ ${ }^{1}$ Department of Neurology, Faculty of Medicine, Public Health, and \\ Nursing, Universitas Gadjah Mada, Yogyakarta, Indonesia \\ 2 Department of Public Health, Faculty of Medicine, Public Health, and \\ Nursing, Universitas Gadjah Mada, Yogyakarta, Indonesia \\ Address for correspondence Paryono, MD, Department of \\ Neurology, Faculty of Medicine, Public Health, and Nursing, \\ Universitas Gadjah Mada, Yogyakarta, Jalan Kesehatan no. 1 Sekip \\ Yogyakarta 55281, Indonesia (e-mail: paryono63@ugm.ac.id).
}

J Neurosci Rural Pract 2022;13:50-59.

\begin{abstract}
Keywords

- home care

- poststroke

- total dependence

- caregiver
\end{abstract}

Objective This study explores the postacute-stroke management problems, particularly for patients with total dependency (Barthel Index $<20$ ), in home care service of Dr. Sardjito Hospital (SH) from the hospital personnel's and caregiver's points of view. Materials and Methods In-depth interviews with a semi-structured interview guide were conducted with hospital personnel and patients' caregivers based on the purposeful sampling. There were 10 hospital personnel that were interviewed: the director of medical service, head of home care unit, neurologists, general practitioners, nurses, and physiotherapist. There were eight caregivers who participated in the study. Statistical Analysis Data from the interviews were analyzed using systematic text condensation using Nvivo 12 plus.

Results Our findings showed that all health personnel in SH agreed that home care service is a part of an integrated health care service for continuation of care. However, the preparedness by the hospital management is still lacking in infrastructures, such as standardized operational procedure, quality control, and financial system, as well as in terms of competent human resources and their welfare. In addition, the patient's family and caregiver are lacking in knowledge and independency to take care of the patients with the need of home care services' monitoring to deliver the expected home care for postacute-stroke's patient regularly.

Conclusion Home care service is an act of implementing hospital obligation to fulfill the patients' rights. An established hospital policy to ensure a comprehensive home care service delivery is necessary. The capability and welfare of the health care personnel should be put into account for the standardized human resources. published online January 14, 2022
DOI https://doi.org/ 10.1055/s-0041-1740613. ISSN 0976-3147.
(C) 2022. Association for Helping Neurosurgical Sick People. All rights reserved.

This is an open access article published by Thieme under the terms of the Creative Commons Attribution-NonDerivative-NonCommercial-License, permitting copying and reproduction so long as the original work is given appropriate credit. Contents may not be used for commercial purposes, or adapted, remixed, transformed or built upon. (https://creativecommons.org/ licenses/by-nc-nd/4.0/)

Thieme Medical and Scientific Publishers Pvt. Ltd., A-12, 2nd Floor, Sector 2, Noida-201301 UP, India 


\section{Introduction}

Stroke is a sudden focal or global neurologic deficit caused by vascular disorder that lasts for more than 24 hours or ends in death. ${ }^{1}$ Stroke cases tend to increase every year and are the second leading cause of death after heart disease, with a mortality rate of 18 to $37 \%$ for the first stroke and $62 \%$ for recurrent strokes. ${ }^{2}$ The main causes of death for all ages in Indonesia are stroke (15.4\%), tuberculosis (7.5\%), hypertension (6.8), and injury (6.5\%). The proportion of communicable diseases in Indonesia in the past 12 years has decreased from 44 to $28 \%$, but the proportion of noncommunicable diseases has increased significantly from 42 to $60 \%{ }^{3}$

Stroke causes disability, and some of them are total dependency indicated by Barthel Index $<20 .{ }^{4}$ The dependent postacute-stroke patient needs comprehensive care from health providers and caregivers. The care management of postacute-stroke patients should be maintained at home after hospital discharge. In some countries, medical home care is managed and provided by the ministry of health, while nonmedical care is provided by other ministries (in Indonesia, by the Ministry of Social Affairs). However, medical and nonmedical components of home care are managed under one integrated management from the two ministries in the Special Region of Yogyakarta with an integrated care pathway. $^{5}$

There are several definitions of home care. Home health care is a system of health care and social services provided at home to people with disabilities or people who must stay at home because of their medical conditions. ${ }^{6}$ Home care can also be interpreted as a unit that allows health services to be performed simultaneously or in combination with various health professions as a team to achieve and maintain optimal client health status. ${ }^{7}$ Home care for patients with postacute stroke, particularly for those with total dependency, is required to ascertain the maintenance of stroke care and risk factors, prevention of complications and major vascular events, and the continuity of rehabilitation. For a good-quality home care performance, health care providers as well as family and caregivers should collaborate in harmony. Unfortunately, home care service in Indonesia is still a luxury with only few people benefiting from the service since it is not covered by the Indonesian National Healthcare Insurance.

Despite the presence of the Home Care Unit in Dr. Sardjito Hospital (SH), a main referral hospital in the Special Region of Yogyakarta, only minority of postacute-stroke patients use the service of this unit. This study aims to explore the policy of Home Care Unit in SH, particularly whether Home Care Unit in SH is prepared for the service used by postacutestroke patients and whether family or caregivers would prefer this service.

\section{Methods}

We considered that qualitative study is an appropriate approach for this research. We performed in-depth interviews with health care personnel involved in Home Care Unit of SH and patients' caregivers.

\section{Sample}

Data were collected between January 2017 and June 2018 in Dr. Sardjito Hospital (SH). Based on purposeful sampling methods, the populations of this study were the health care personnel consisting of the director of medical service of $\mathrm{SH}$, the head of Home Care Unit of $\mathrm{SH}$, two attending neurologists, two general practitioners, two nurses, two physiotherapists, as well as three family caregivers and five caregivers of the postacute-stroke patients (-Table $\mathbf{1}$ ). The stroke patients were selected from the postacute ischemic-stroke patients who received home care service from $\mathrm{SH}$ between the periods of January 2017 and June 2018. Sampling was continued to the point of data condensation.

\section{Data Collection}

Qualitative data were collected through focused group discussion (FGD) followed by semi-structured in-depth interviews with the director of medical service of $\mathrm{SH}$, head of Home Care Unit of $\mathrm{SH}$, attending neurologists, general practitioners, nurses, and physiotherapists; and in-depth interviews with stroke patients and their caregivers. The research questions for FGD and in-depth interview were designed using semi-structured guide. By using open-ended questions, FGD and in-depth interviews explored the participants' roles, experiences, and knowledge in home care services in SH. Interview protocolconsisting guide for the interview implementation and interview guide listing the research questions were reviewed and refined by the research group (-Supplementary Appendix S1, available in the online version only).

FGD and in-depth interviews were conducted by a team that was trained in qualitative research technique under the supervision of two authors. The team consisted of two persons, the first person was the main interviewer who had the conversation with the participants and the second person was in charge for recording and time keeping. All participants were informed and consented before the beginning of the FGD and in-depth interviews regarding the research purpose and confidentiality. FGD and in-depth interviews with the health personnel were performed in the meeting room of $\mathrm{SH}$ at the agreed time and lasted for 60 to 120 minutes. On the other hand, in-depth interviews with the stroke participants and their caregivers were conducted separately at the participant's house, according to the agreed time. The meeting was performed for 60 to 90 minutes for at least one session and some participants were interviewed twice to explore themes that seemed unclear or ambiguous. To ensure the validity of this study, triangulation was conducted. $^{8}$

\section{Data Analysis}

Data analysis was performed to identify the studied phenomenon based on existing data on the audiotapes using Nvivo 12 plus (QSR International Inc., Massachusetts, United States). Existing data were transcribed word by word and then analyzed by the authors through several stages: (1) reading through all the experiences to get an overall picture, (2) rereading the description, (3) identifying the transitional units of the experience, (4) clarifying and elaborating the 
Table 1 Characteristics of the health personnel and caregivers $(N=18)$

\begin{tabular}{|c|c|c|c|c|c|c|c|}
\hline Subject & Age & Sex & Education level & Profession & Race & Religion & Marital status \\
\hline P1 & 55 & M & Master & Hospital director & Javanese & Islam & Married \\
\hline P2 & 60 & $\mathrm{~F}$ & Bachelor & Head of Home Care Unit & Javanese & Islam & Married \\
\hline P3a & 56 & $\mathrm{M}$ & Doctorate & Neurologist & Javanese & Islam & Married \\
\hline P3b & 50 & M & Master & Neurologist & Javanese & Islam & Married \\
\hline P4a & 32 & $\mathrm{~F}$ & Bachelor & General practitioner & Javanese & Islam & Married \\
\hline P4b & 30 & $\mathrm{~F}$ & Bachelor & General practitioner & Javanese & Islam & Married \\
\hline P5a & 38 & M & Bachelor & Physiotherapist & Javanese & Islam & Married \\
\hline P5b & 26 & $\mathrm{~F}$ & Bachelor & Physiotherapist & Javanese & Islam & Married \\
\hline P6a & 25 & $\mathrm{~F}$ & Bachelor & Nurse & Javanese & Islam & Married \\
\hline P6b & 26 & $\mathrm{~F}$ & Bachelor & Nurse & Javanese & Islam & Married \\
\hline P7a & 60 & $\mathrm{~F}$ & High school & Family caregiver & Javanese & Islam & Married \\
\hline P7b & 55 & $\mathrm{~F}$ & High school & Family caregiver & Javanese & Islam & Married \\
\hline P7c & 36 & $\mathrm{~F}$ & Bachelor & Family caregiver & Javanese & Islam & Married \\
\hline P7d & 24 & $\mathrm{~F}$ & High school & Caregiver & Javanese & Islam & Married \\
\hline P7e & 36 & $\mathrm{~F}$ & High school & Caregiver & Javanese & Islam & Married \\
\hline P7f & 23 & $\mathrm{~F}$ & High school & Caregiver & Javanese & Islam & Married \\
\hline P7 g & 25 & $\mathrm{~F}$ & High school & Caregiver & Javanese & Islam & Married \\
\hline P7h & 20 & $\mathrm{~F}$ & High school & Caregiver & Javanese & Islam & Married \\
\hline
\end{tabular}

meanings by connecting constituents to one another thoroughly, (5) transforming native language into concepts, (6) condensing and summarizing the concepts, and (7) integrating and synthesizing the insights gained into descriptive structures to get the meaning of experience. ${ }^{9}$ The analysis was compiled in a document that was used as a source for all authors to discuss. The results of this qualitative data analysis were triangulated between the interviews with health care personnel, families, and caregivers.

\section{Ethics}

Ethical approval for this study was obtained from The Ethical Committee of Faculty of Medicine, Public Health, and Nursing, Universitas Gadjah Mada No. KE/FK/0782/EC/ 2020. All participants were well informed about the study, including the right to withdraw at any time, and gave their written consent at the time of recruitment.

\section{Results}

From our interviews, we found that all health personnel in $\mathrm{SH}$ agreed that home care service is important since it is part of an integrated health care service. The director of SH had issued a director's regulation on the establishment of Home Care Unit in SH in 2012. However, obstacles were met in many aspects during the implementation of this policy. Our findings showed that the infrastructures, ranging from standardized operational procedure, medical record, quality control, and home care financial system, as well as competent human resources and their welfare might be the main problems that the health personnel had been facing at the home care service of SH when they performed their roles. In addition, the caregivers of the postacute-stroke patients were lacking in understanding and capabilities to independently take care of the patients at home after hospital discharge. The collaboration of the hospital personnel in home care service and the willingness of the caregivers to take care of the patients are needed to maintain the patients' well-being.

\section{Home Care Service Policy Is the Hospital Obligation to Fulfill the Patients' Rights}

One of the premises to establish a home care service in $\mathrm{SH}$ is the obligation to fulfill the Government Regulation No. $44 / 2009$, Article 32 , about patients' rights in the hospital. ${ }^{10}$ The aim of the home care service is to make sure that the patients' care is continued properly at home. Although the service is given at the patients' residents, a legal informed consent is made at the hospital before the commencement of home care service by the Home Care Unit of SH. The concept of the home care service in SH for postacute-stroke patients is mutual understanding between the health care providers, patients, and patients' caregivers to provide care, not to promise a cure or increase outcomes.

"So one of the things that must be built in understanding the concept of rights and obligations between patients and hospitals is mutual understanding, yes, mutual understanding. Secondly, it must also be understood that health services are not promising outcomes or results, but promising efforts. ... Once again, close relationship between health workers and their families and 
patients is important. That standardization needs to be developed." (P1)

"We just follow the rights and obligations that are used in the hospital. But we have an informed consent form in registration process. So there are signed forms regarding patient's approval after being given clear explanation. We're just following the usual arrangements." (P2)

As for the care of postacute-stroke patients, home care service is provided for the total dependence patients. It is now considered that the demand of home care service is increasing. In addition to continuing the care management of the patient, home care service is also directed to include promotion, prevention, curative, and rehabilitation programs.

"Dr. Sardjito Hospital is obliged to ensure that patients treated in Sarjito are receiving continous[sic] care, where there are about 20\% of stroke patients with total dependence requiring further treatment, by providing home care services." (P1)

"Its development has never declined, it has continued to rise. ... So, in my opinion, it really needs to be managed professionally, because it is indeed their interest. ... What is clear, because the needs of the community are high, so I hope quality of service is the number one priority... The service must be professionals, and that home care is not only for palliative, but also promotive, preventive, curative, rehabilitative and palliative." (P2)

From the hospital's perspective as a business strategy, home care service is certainly expected to make a positive contribution to the hospital, in terms of financial aspects and reputation. However, to date, home care service is not considered as the primary service offered by the hospital to attract many patients.

"This means that, public service can not only be valued from the moment of generating profit or not. But in a certain period of time, from the business perspective it's not only daily transactions, but weekly and monthly transactions. Just look at it after we have new home care service or other services, the transactions at Sardjito are not only the home care, Sir... That's what we build, networking. In the homecare, but later on, we can get profit from overall health spending. So don't be narrow-minded and focus on the performance of just one unit." (P1)

\section{The Infrastructure Problems of Home Care Service in RSUP Dr. Sardjito Hospital for Postacute-Stroke Patients}

\section{Standardized Operational Procedures of Home Care Services}

During the implementation of any program in an international standardized hospital, a standardized operational procedure is necessary. Although it has already been established in outpa- tient and inpatient services, there is no standardized operational procedure in home care service of Home Care Unit in SH. It is necessary to establish a standardized operational procedure for home care service. Thus, operating the home care service according to the standardized operational procedure is legally and practically safe.

"So, there is SOP (standardized operational procedure) in standardization, there is an existing policy. In standardization, there should be control, monitoring, and evaluation. So, it means that the standardization that can always be revised in accordance with the evaluation results and evolving needs. Then, what is more important is how to set-up patient facility at home. How to make compatible environment for safe service delivery. For example bathroom design, bedroom design, closet design in patients who need home care is precisely the highest patient safety factor, which is now still not much appreciated, so there should be one agency or another team that assess the readiness of the design, a particular design of the spoon must also be considered." (P1)

"I only followed JCI. But, actually, JCI is designed for outpatient and inpatient care, there is no home care. So, I keep making, but by my own opinion, I adjust it. Oh, this is the standard in inpatient services. I guess it's the same at home care. Some that are similar, I took it." (P2)

"Yes, with hospital by law, everything is safe. It means that it is protected by law. So, less emergency case is managed at home care, if it's still, if there is still emergency, then it should be treated at the hospital." (P3b)

\section{Medical Recording Problems}

In the past 7 years, to face the 4.0 industrial revolution era, $\mathrm{SH}$ has developed integrated e-medical record managed by medical record installation. It is now making the medical services, both inpatient and outpatient, more effective and efficient. However, Home Care Unit is not yet linked to the integrated e-medical records. This resulted in poor home care service collaboration and difficulty in reviewing the patients' conditions.

"In the future we will, once again, we will further implement the use of E-Medical Records including IT and developing technology related to internet, including data that will later be collected from these services will also be recorded in the big data. ... Once again, Sardjito has gradually implemented the E-Medical record." (P1)

"Medical record ... here at half to eight everyone is ready, at quarter to eight we usually already hold the morning meeting, in preparation to go to the field. Well, because it is early morning usually medical records installation will not be willing to serve us that early so we have to deal with that... we manage medical records by ourselves, like that."(P2) 
"The quality of stroke patients management that is carried out post-hospitalization by the home care team does not only depend on clinical problems. But it is also non-clinical or administrative. Thus it needs is a standard medical record integrated with the hospital medical record to confirm the medical record during his hospitalization at Sardjito Hospital. Medical records forms for stroke patients should be created or developed by the hospital home care team, including what contents are necessary, how the follow-up is handled, who performed it." (Р3a)

\section{Home Care Service Quality Control}

Home care service quality control in SH is stated in the policy of guideline development in every service activity for patients. It is necessary to refer to the clinical care pathway to control the medical service quality. However, the home care service in $\mathrm{SH}$ was lacking of an integrated clinical care pathway.

"To provide the service, we follow clinical pathway, whether it is available or not yet available, it is indeed a homework that has to be done, but there are also SOP. So, it means, the core is the clinical pathway, but later on for procedures there are SOP, it must be created and updated continuously." (P1)

"Stroke management guidelines conducted by the Sadjito Home Care Team, the management is also general. So, if it is a stroke patient, to be honest, there is no specific guideline yet. The obstacle is that there is no clinical pathway for homecare service here." (P3b)

"For stroke patients specifically there are No. specific guidelines, we only rely on our competence. If it is necessary, we still consult the attending neurologist. Because the problem of stroke patients themselves is usually not because of the disease, but the result of stroke itself, for example stroke complications." (P4a)

“Not yet doc. For stroke, not yet." (P5a)

“For specific ... for specific case, not yet." (P5b)

"Oh, for physiotherapy, we have, doc. But, we don't specifically have for this ... very specific we have our own ... No." (P6a)

"Yes, the evaluation is through the medical record form that describes the subjective, objective, assessment and planning. What date did he come, when was he scheduled to come, when was the control and so on. Even if it is necessary, if found other things or complication, it can be referred by neurologist to other relevant specialists." (P3a)

"In practice ... we have the ADL (activity daily living). We evaluate the $A D L$, yes." (P3b)
As a result, there was no standardized care during home care visit for postacute-stroke patients. There was no standardized operational procedure among doctors, nurses, or physiotherapists when they perform home care visit. Besides providing continuous care, the main role of home care services is to educate the patients and their families. Every health personnel would perform home care visit according to their own understanding of what the patients may need because there is no standardized operational procedure, integrated clinical care pathway, specific care plan, and integrated medical records. Furthermore, it would be difficult to evaluate the results of the care from the previous home care visit since there is no integrated medical records, specific care plan, or standardized evaluation tools for every patient, since different health care providers visit and perform home care service for the patients in a determined period of time, either daily, weekly, or monthly.

"At first we explain to the patient's family about the dependency of post-acute stroke patient, because the general public's paradigm thinks why the patient was discharged when they had not been able to carry out daily activities. Therefore, explanations must be given related to the dependency of these patients is a residual symptom of the stroke, and this home care service aims to improve the patient's condition. Then we look at the patient's environment, because the patient is a high risk patient, so we must educate the patient's family, and evaluate the diet." (P4a)

"The first thing we do is a complete examination, including patient awareness, vital signs and we explored all. At the beginning of the examination at home, we usually evaluate the problems that were brought home from the hospital, make sure we have data and remember the patient's problems. After we evaluate and provide treatment for the patient, we also educate the patient's family. Because the progress of the patient also depends on the support of the family itself." (P4b)

"We often see it from the wound care, with a target of three months for wound improvement, that we already have. Because we mostly do wound care, doc. Wound care and NGT that take a long time. Even though it's slow, it's usually improving." (P5a)

"For evaluation procedure we also ask for family approval first. For example, the family wants it to be only once per week." (P5b)

"Yes, depending on the progress. So, no waiting, don't have to wait for me, sometimes the condition is fluctuative. Some are stable, some are unstable." (P6a)

"For patients, especially physiotherapy evaluation is done every month. Initially we set the goal of ADL improvement for these patients. In practice, it hasn't been achieved, it doesn't matter, but we have ADL or measurable goals. So, it depends on us." (P6b) 


\section{Financial Problems}

Indonesian National Healthcare Insurance did not cover the fee for home care service. Therefore, according to the hospital policy, home care services cost should be reasonable compared with the cost of inpatient care.

"Home care service must be cheaper than inpatient services, if indeed it is needed, two things can be done: 1 . Sell the premium, service will be covered. 2. We must involve the community.... If the patient doesn't have money, we have to facilitate the patient's family to be independent. Self sufficient is the keyword at the Ministry of Health. So, in principle we cannot force National Health Insurance to cover home care services." (P1)

Without the coverage of Indonesian National Healthcare Insurance, home care service is certainly unattractive for patients. To date, home care service is an out-of-pocket service directly paid by the patient. It had not been integrated with the hospital's financial system and there is no standardized payment.

"There is no standardisation of the payment procedure for home care personnels who do home visit. So far, it still uses the fees determined by the hospital, but not based on unit costs. So rather not consider if there is any complication, do not consider distances, do not consider how many people are involved in. It should be calculated in unit costs. Now this is a financial obstacle. Well, and even then there are other financial constraints that the type of the payment is from individuals to individuals. Ideally, it is from patients to institutions." (P3a)

According to the mutual understanding between the health care personnel and patients or patients' caregivers, the payment system is also informed and consented. The home care service manager preferred the payment to be made in advance of the provided service to avoid any misconduct from both parties.

"Well, in the past the payment was paid later after the service had been given. But, I was cheated till I could not collect millions of money. So pity for the healthcare personnels who had already worked hard. Like that. So, now I make a deposit system. Indeed I did not make a package, because every patients needs are different." (P2)

\section{Human Resources and Their Welfares Affecting Home Care Service in Home Care Unit of Dr. Sardjito Hospital}

Lack of Capable Human Resources in Home Care Service Unit

SH already had systems and regulations in terms of human resources development to catch up with the development of the latest medical science and technology. However, weak leadership becomes an obstacle in continuing the medical education for knowledge and skill improvement of every health personnel. On the other hand, there is a need for each health personnel to be able to perform their tasks with the same standards.

“... Informally, I have also stated to the directorate of medical and nursing that each employee must be able to master one new skill each year. If the skills improvement is related to the line of work, we will afford it financially. Our employees are currently have difficulty in learning, in other words, Learning Disability." (P1)

"Now, we hope for this home care unit personnels, each member has a specialization related to the task specification, to optimize the care for stroke patients in particular." (P3a)

All general practitioners and nurses who are working in home care services of $\mathrm{SH}$ have received training for the management of neurological patients. However, lack of continuing medical education routinely for specific knowledge and skill refreshing made the health care personnel focused only on patient's general care, such as managing the noticeable wound care without performing thorough examinations on possible other complications of poststroke.

"Not too often attending seminar about stroke management, last time it was 1 year ago." (P4a)

"Wound care course, basic neurology, mostly in the wound care, twice in wound management." (P5a)

"Maybe just some seminars, the topic ... neurology once. But already in the 2014s." (P5b)

"Uh, the last time if I may say it in order, eh Bobath course. That was introductory, just the beginning. Then followed by integrated and multidisciplinary approach on physiotherapy at, eh, Singapore General Hospital, precisely at the academia during the 2018 stroke congress. In addition, there are several courses related to management on, eh... eh... Rehabilitation and Integrated Cancer Course in Singapore 2017." (P6a)

Human resources' quality and quantity are necessary to be improved for further development of home care services unit, given the potential public interest in the home care services. This, in turn, will affect the quality of the provided home care services and the performance of the home care services unit in $\mathrm{SH}$.

"Lack of human resources is a burden for home care services, so the primary need is human resources, we have a lot patients to serve and are spread in many areas." (P4a)

"It is very often that we are getting sick alternately, among us. For example, I have to take a day off since I am too sick to work, usually catching a cold or getting dizzy, my friend would got overloaded with work for several days to also cover my work. And then, in turn, he will need to take a day off after that." (P5a)

"Do you mean in a week? That depends on the initial management plan. Then, depending also on, what the term is, restrictions are possible. But ideally for the acute 
phase of stroke that I know of, I would be scheduled for 2-3 visits per week within the first 3 months of stroke phase. But usually we fulfill only 2 times because of limited personnels." (P6b)

\section{Home Care Services Unit Staffs' Welfare Needs More Attention}

Currently, there is no standardized incentive for home care staff. This makes home care service unattractive for staffs to be involved in.

\begin{abstract}
"Yes, so far because it is a social indication. And the variability is high. There are those who just say thank you, only give gifts, and some money only around 200 thousand to 300 thousand Rupiah (13-20 USD) per visit. The highest is only 300 thousand Rupiah (20 USD), without considering the distance. So, that sometimes increases the inconvenience. In the end, we just say 'we only got that much, instead of split it and get too little, let's just buy some food' usually just like that." (P3b)
\end{abstract}

General practitioners and nurses as the main personnel who performed the medical tasks in home care services expected more consideration from management regarding safety and incentive according to the level of risks that they faced daily. The nurses said that overall they were satisfied with the current condition, but there were several things that can certainly be improved, especially in terms of benefits and incentives.

"The trip to the patient's house for each visit could take a half to an hour, from one house to another house. Sometimes it's hot or raining, but we keep on going. So, hopefully there will be more appreciation for us as home care doctors. Transportation is also an obstacle. Hopefully, the director can provide a means of transportation for home care services." (P4b)

“(I am) satisfied. Even though I heard that our takehome pay is less than they are who take shifts in the ward. But, so far, we are quite satisfied, because we understand they also have night shifts, we have different levels of stressors. So with this takehome pay, I am quite satisfied. Yes, at my own risk. The vehicle are still fully on our own." (P5a)

"The welfare of the staffs ... I don't think so ... yesterday we have proposed ... for example, we ride our own vehicles to reach the patient's house. There is also no consideration of risk and takehome pay. There is transport allowance. But the payment is uncertain, that's why." (P5b)

"Yes, improvement in everything is needed. In terms of human resources too, then eh, welfare." (P5b)

\section{The Caregivers' Perspectives and Obstacles on the Home Care of Postacute-Stroke Patients}

In taking care of the postacute-stroke patients, the primary caregivers would be someone from the family, for example the patient's son or daughter, also called as family caregiver, or someone who is hired by the patient's family to take care of the patient, also called a trained caregiver. The family caregiver would usually be around the patient for 24 hours everyday while the trained caregiver could be shifted into day or night shift.

\footnotetext{
“We were there for the patient, 24 hours, everyday." (P7a)

"Yes, almost 24 hours, 10 hours for day shift and 12 hours for night shift." (P7c)
}

"For me, I do it almost every hour, the problem is to give the food, it is really hard, really hard." (P7h)

Generally, both family and trained caregivers' knowledge of stroke is still limited. They felt some difficulties in understanding what is going on with postacute-stroke patients.

"I think the disruption of body function. So, apparently the next disturbance was more ... more than eee. At that time my husband was told of a disturbance ... um ... what is a clot... what is it called ... We have to be careful if next stroke attack might happen." (P7d)

“I don't really know anything about strokes, I know from my experience, I mean after I ... am taking care of my mother, nothing happened, suddenly ... eee ... for example she fell off, disturbed body function, one of the nerve function in any part ... eee ... the disturbance makes the patient unable to move or walk." (P7f)

As a result, caregivers' knowledge to take care of the postacute-stroke patients in the prevention of recurrent stroke is not comprehensive. Mostly, caregivers who use the home care services would only rely on the health personnel to thoroughly care for the patients and evaluate the patient's general condition.

"I don't know, but from that doctor ... eee ... the doctor who examined, I mean the home care doctor who periodically come, it has something to do, with the condition ... So, if a stroke patient is ... it's awry, so sometimes we give medicine." (P7c)

"For the treatment, it is usually from the doctor who managed the patient, that's the first, then from the family as well, then from physiotherapist too." (P7a)

For example, to prevent decubitus ulcers, caregivers would mostly rely on antidecubitus mattress and applying oily cream on the patient's back. They rarely performed simple passive mobilization to put the patient in his/her side to avoid chronic pressure on the patient's back due to supine position. In addition, caregivers' treatment to the patient is only based on information from health personnel who come to visit the patients. They rarely seek information from other sources, such as Internet. 
"Yes, so usually there is. But, sometimes I have ideas. 'Oh if it is applied, it turns out like this. My mother seems more comfortable like this'. Sometimes I don't change, sometimes I add. For example, sometimes 'if she was applied with oil, because it's been a long time' it seems she felt bored." (P7b)

"The thing is we are afraid that we will be blamed, there was someone said to me, "How dare you do that," even though actually we were doing our best..." (P7e)

"Yes, from me, the point is ... that's .... we give it, this is the simple one, we gave oil. We have to do it every day, we put the patient on his side, left side, right side, together with the nurse." (P7f)

The biggest obstacle experienced by the caregiver is communication with patients. For trained caregivers, the communication with the patient's families was difficult, sometimes. In addition, the patient's and family's psychological condition could also be a barrier in delivering the care for the patient.

"The obstacle, for me, is the mood, the mood of the patient. He actually wanted to be treated by his children... to take care of all his needs. But, because the children are indeed busy at work, so it was given to me. We found it difficult to care for him if his mood is not good." (P7e)

\section{Discussion}

This study highlights the infrastructures, systems, and readiness of $\mathrm{SH}$ related to home care services. All health care personnel, including the director of medical service, head of home care unit, neurologists, general practitioners, nurses, and physiotherapist, agreed that home care service is necessary in $\mathrm{SH}$ as it is a hospital obligation to make sure the continuation of patient's care, even after being discharged from the hospital. Despite the establishment of the director's regulation regarding the home care service in $\mathrm{SH}$, the standardized home care service is not yet provided due to many obstacles. Although the home care service in $\mathrm{SH}$ is faced with many obstacles, the health care personnel still conduct home care visit for patients with total dependency since it is necessary to continue the care for the patients and the education for the patients' caregivers.

\section{Infrastructure Improvement is Necessary for Better Home Care Services in SH}

Home care as a unit allows health services to be performed simultaneously or in combination with various health professions as a team to maintain optimal health status, maximize the degree of independence, and minimize the disease consequences of the patient. ${ }^{7}$ This aims to facilitate promotion, prevention, curative, and rehabilitation programs. Home care services improve the patient's recovery because health care is performed at home, a place filled with a sense of comfort, and also the relationship between physical and emotions. ${ }^{11}$
Compared with hospital visit, home care services are more preferred by the patient's family or caregiver. ${ }^{12}$ In fact, home care services are beneficial for caregivers as they can reduce the number of caregiver burden scores and increase quality of life, especially in mental dimensions and vitality. $^{13-16}$

\section{Home Care Services in SH: Policy vs Reality}

The Government Regulation No. 44/2009, Article 32, stated that every patient has the right to obtain humane, fair, honest, and high-quality health services, without discrimination in accordance with professional standards as well as effective and efficient standardized operational procedures to avoid physical and material losses, and receive information regarding his/her diagnosis, medical procedure, the purpose of medical procedure, alternative procedure, possible risks and complications, prognosis, as well as estimated cost of treatment. In addition, patient has the rights to complain about hospital services that are not in accordance with service standards through print and electronic media in accordance with statutory provisions. ${ }^{10}$

One of the patient rights that must be fulfilled by the hospital is to get services with standards in accordance with the provisions of the applicable laws and regulations. Despite the policy, not all patients' needs were fulfilled properly because the ratio between patients and medical staff available at the home care services unit is not ideal. Patients' rights are fulfilled by creating mutual understanding and negotiating between management and patients. This includes risk assessment, patient identification and risk management, incident reporting and analysis, the ability to learn and follow-up on incidents, and implementing solutions to reduce and minimize risk occurrence. Integrating human rights training for health care providers at all levels is essential. ${ }^{12}$ To maintain patient safety, it is recommended that negligence errors should be a safety priority, including focus on preventive health care interventions and implementing of the following five steps that can improve patient safety by changing physician behavior. According to Cook et al (2004), ${ }^{17}$ the five steps are: (1) environmental scanning, (2) understanding current behavior, (3) target behavior for change (why, what, when, where, and who), (4) adopting effective strategies for changing behavior, and (5) synergize.

Regulation of the Minister of Health of Republic of Indonesia No 1438/MENKES/PER/IX /2010 Regarding Medical Service Standards, Article 3, stated: (1) Medical service standards include National Medical Service Guidelines (NMSG) and standardized operational procedure (SOP); (2) NMSG as referred in Clause 1 is a national Medical Service Standard and is made by professional organizations and approved by the Minister; and (3) SOP as referred in Clause 1 is made and determined by the head of the health service facility. Article 10 stated: (1) The head of the health service facility shall initiate SOP development according to the type and level of the health service facility he leads; (2) NMSG must be used as a reference in the development of SOP in the health service facility; (3) SOP must be used as a guide for all health workers in health care facilities in providing health services; (4)SOP is prepared in the 
form of Clinical Practice Guidelines that can be supplemented with clinical pathways, algorithms, protocols, procedure, or standing order; and (5) Clinical Practice Guidelines as referred to in Clause 4 must contain at least the definition, history taking, physical examination, diagnostic criteria, differential diagnosis, supporting examinations, therapy, education, prognosis, and literature. ${ }^{18}$

Despite the policy, care pathway and standardized operational procedures in Home Care Unit of $\mathrm{SH}$ are not yet established. To commence the quality improvement process, it is necessary to apply the following steps: (1) problem identification, (2) analysis of the causes of the problem, (3) solution development, (4) implementation, evaluation, and solution refinement, and (5) permanently implementing the health system and improving the solution. ${ }^{19}$

Another infrastructure problem of home care services in $\mathrm{SH}$ is the disintegrated medical records from the hospital's e-medical records. Medical records are compilations of scientific data from various sources, coordinated into documents and available for various personal and impersonal uses. According to Government Regulation of Republic of Indonesia No. $44 / 2009$, SH is required to organize medical records, as a form of reflection of accountable health services. ${ }^{10}$ Conventional medical records are writings/notes/documentation that chronologically and systematically describe and explain the medical history of a person's diseases. Difficulties in filling medical record in home care services always become a burden, for instance when home care nurses must maintain interaction with the patients, including eye contact and other services, making it difficult for nurses to fill out medical records while providing home care services. A strategy to overcome this is to remember what needs to be documented and write it later. ${ }^{20,21}$

Electronic health record (EHR) can also be implemented in home care service. A study reported that with the implementation of EHR, there was a high level of satisfaction from clinicians especially in the sub-items of completeness and data accuracy. In addition, the highest impact was found on the timeliness of filling the EHR and the ease of insurance claims. ${ }^{22}$ The focus of patient care process optimization is the utilization of Internet-based and interconnected information technology systems to attain efficient and effective services. ${ }^{23}$

According to SH's policy, home care services cost must be more efficient than inpatient care with mutual cooperation principle. Until now, the income of the home care services unit has been directly paid by patients and has not been integrated with the hospital's financial system. Home care services are not covered by Indonesian National Healthcare Insurance and only covered by private insurances. This needs to be reconsidered. In European countries, home care services are provided by the government and continue to grow realizing the importance of home care services, although some countries such as Germany, Netherlands, and Spain still have not implemented home care services into centralized health financing. ${ }^{11}$

The average total cost for home care services is lower than outpatient services in hospitals. Standard rate calculation should consider complication, risk factor, and worsening of clinical condition. Patients who received home care services had higher average increase in the Barthel Index than who received outpatients' care. From qualitative perspective, patients and their families were quite satisfied with home care services and prefer home care services rather than outpatient services in hospitals. ${ }^{24}$

\section{Improvement in Human Resources' Capabilities and Welfare is Necessary}

According to Setyawati (2004), ${ }^{25}$ home care team includes the following staffs: (1) health professionals group, including nurses or professional nurses, doctors, physiotherapists, occupational therapists, speech therapists, nutritionists, radiologists, medical laboratory technologists, and psychologists; (2) nonhealth professional groups, including social employees and spiritual leaders or religious experts; and (3) nonprofessional groups, including nurse assistants who serve as assistants waiting to serve the needs or daily activities of the client (caregiver). This group works under the supervision and direction of the nurse. However, it is not easy to maintain many parties involved in home care services due to diverse clinical and organizational decisions, and the difficulty of uniting medical personnel. ${ }^{26}$

The constraints regarding the human resources in home care services were insufficient number of staff and lack of human resources recruitment strategies. This can be seen from four aspects: (1) compensation, that is, staff felt not getting enough compensation and compensation also varied across countries, (2) education and training, (3) quality assurance, and (4) working environment conditions. Considering these four aspects, the strategy that can be employed in recruitment should include giving trial periods for applicants and offering training programs. In addition, in terms of compensation given there are also recommendations for attracting applicants, along with other benefits. ${ }^{27,28}$

Staff welfare has been regulated in a performance-based take-home pay system. However, staff still felt the amount is unattractive because it does not consider the risks of providing services outside the hospital. Service quality is directly affected by employee benefit policies and sustainability. Incentive is a good way to motivate performance and loyalty of employees, especially employees from service sector. ${ }^{29}$

The reward system expresses and reinforces the values and norms that shape company culture. A careful consideration of reward system design can help decision-makers succeed by modifying organizational culture. Reward system is basically a powerful mechanism that can be used by managers to communicate desired attitudes and behaviors to members of the organization. It is believed that over time, culture can accept change through clear communication of performance, as well as consistent criteria and application of rewards. ${ }^{30}$

\section{Conclusion}

Home care services that are provided by a hospital is necessary, according to the health care providers as well as patients' caregivers, as an integrated health care service to ensure the continuing care for patients in need, such as postacute-stroke patients with total dependency. It is an act of implementing hospital obligation to fulfill the patients' 
rights, as stated in the Indonesian Constitution and Government Regulations. However, many challenges are met upon the implementation of this policy.

A good-quality home care service depends on the preparedness of the home care services unit to provide good care for maintaining the patient's welfare after hospital discharge. Although the system is based on mutual understanding between the hospital and patient's family, an established hospital policy to ensure a comprehensive home care service delivery is necessary, such as standardized operational procedure, care pathway, medical recording, and integrated financial system. The capability and welfare of the health care personnel should be put into account for the standardized human resources.

\section{Authors' Contributions}

Paryono, MD, was involved in conception and design, administrative, technical, and logistic support, data collection and assembly, data analysis, and drafting the article.

Mawaddah Ar Rochmah, MD, PhD, was involved in drafting the article, data analysis, and administrative, technical, and logistic support.

Ismail Setyopranoto, MD, $\mathrm{PhD}$, was involved in conception and design, data analysis, obtaining funding, final approval of the article.

Laksono Trisnantoro, MD, PhD, was involved in provision of study material, critical revision of the article, and final approval of the article.

\section{Conflict of Interest}

None declared.

\section{Acknowledgments}

The authors are indebted to the health care personnel, poststroke patients, and their caregivers who willingly participated in this study.

\section{References}

1 Johnson W, Onuma O, Owolabi M, Sachdev S. Stroke: a global response is needed. Bull World Health Organ 2016;94(09): 634-634A

2 World Health Organization. Noncommunicable Disease Country Profiles 2018. Geneva: World Health Organization; 2018

3 Ministry of Health of Republic of Indonesia. Health Profile in Republic of Indonesia 2019. Jakarta: Ministry of Health of Republic of Indonesia; 2020

4 Wade DT, Collin C. The Barthel ADL Index: a standard measure of physical disability? Int Disabil Stud 1988;10(02):64-67

5 Social Department of Daerah Istimewa Yogyakarta. Technical Guidelines of Home Care. Yogyakarta, Indonesia: Social Department of Daerah Istimewa Yogyakarta; 2007

6 Nies MA, McEwen M. Community Health Nursing: Promoting the Health of Populations. 7th edition. St.Louis, MO: Elsevier Health Sciences; 2018

7 Smith CM, Maurer FA. Community Health Nursing: Theory and Practice. 2nd edition. Philadelphia, PA: Saunders; 2000

8 Creswell JW. Qualitative Inquiry and Research Design: Choosing among Five Approaches. 3rd edition. Thousand Oaks, CA: SAGE Publications; 2013
9 Streubert HJ, Carpenter DR. Qualitative Research in Nursing: Advancing the Humanistic Imperative. Philadelpia, PA: Lippincott; 1999

10 Government of Republic of Indonesia. Government Regulations of Republic of Indonesia No. 44/ 2009 in regards of Hospital. Jakarta, Indonesia: Government of Republic of Indonesia; 2009

11 World Health Organization. The Solid Facts: Home Care in Europe. Geneva: World Health Organization; 2008

12 Cohen J, Ezer T. Human rights in patient care: a theoretical and practical framework. Health Hum Rights 2013;15(02):7-19

13 Mant J, Carter J, Wade DT, Winner S. Family support for stroke: a randomised controlled trial. Lancet 2000;356(9232):808-813

14 Grant JS, Elliott TR, Weaver M, Bartolucci AA, Giger JN. Telephone intervention with family caregivers of stroke survivors after rehabilitation. Stroke 2002;33(08):2060-2065

15 Kalra L, Evans A, Perez I, et al. Training carers of stroke patients: randomised controlled trial. BMJ 2004;328(7448):1099

16 Ugur HG, Erci B. The effect of home care for stroke patients and education of caregivers on the caregiver burden and quality of life. Acta Clin Croat 2019;58(02):321-332

17 Cook DJ, Montori VM, McMullin JP, Finfer SR, Rocker GM. Improving patients' safety locally: changing clinician behaviour. Lancet 2004;363(9416):1224-1230

18 Ministry of Health of Republic of Indonesia. The Regulation of Ministry of Health of Republic of Indonesia No.1438/MENKES/PER/IX/2010 in regards of Basic Principles of Medical Service Standards. Jakarta: Ministry of Health of Republic of Indonesia; 2010

19 Massoud R, Askov K, Reinke J, et al. A Modern Paradigm for Improving Healthcare Quality. MD: Quality Assurance (QA) Project; 2001

20 Moody LE, Slocumb E, Berg B, Jackson D. Electronic health records documentation in nursing: nurses' perceptions, attitudes, and preferences. Comput Inform Nurs 2004;22(06):337-344

21 Yang Y, Bass EJ, Bowles KH, Sockolow PS. Impact of home care admission nurses goals on electronic health record documentation strategies at the point of care. Comput Inform Nurs 2019;37 (01):39-46

22 Sockolow PS, Bowles KH, Adelsberger MC, Chittams JL, Liao C. Impact of homecare electronic health record on timeliness of clinical documentation, reimbursement, and patient outcomes. Appl Clin Inform 2014;5(02):445-462

23 European Union Agency for Network and Information Security (ENISA). Smart Hospitals, Security and Resilience for Smart Health Service and Infrastructures. Attiki, Greece: European Union Agency for Network and Information Security (ENISA); 2016

24 Center of Health Financial Policy and Insurance Management Universitas Gadjah Mada. Unit Cost Di Rumah Sakit Perlukah. Yogyakarta: Center of Health Financial Policy and Insurance Management Universitas Gadjah Mada; 2015

25 Setyawati. Pengembangan Model Praktek Mandiri Keperawatan di Rumah (Home Care). Paper presented at: 2004 Seminar of Home Care Nursing in the Global Era: Continuing Nursing Education of Nursing Study in Faculty of Medicine Universitas Muhammadiyah Yogyakarta; 2004; Yogyakarta, Indonesia

26 Borsani V, Matta A, Beschi G, Sommaruga F A Home Care Scheduling Model For Human Resources. Paper presented at: 2006 International Conference on Service Systems and Service Management, IEEE, p. 449-54; October 25-27,2006; Troyes, France

27 Keefe JM, Knight L, Martin-Matthews A, Légaré J Key issues in human resource planning for home support workers in Canada. Work 2011;40(01):21-28

28 Home Care Sector Study Corporation. Canadian Home Care Human Resources Study: Synthesis Report. Canada: Canadian Home Care Human Resources Study; 2003

29 Mehmood S, Ramzan M, Akbar MT. Managing performance through reward system. J Humanit Soc Sci 2013;15(02):64-67

30 Kerr J, Slocum JW. Managing corporate culture through reward systems. Acad Manage Perspect 2005;19(04):130-138 